\title{
Surface Immunoglobulin Positive Cells Present
}

National Cancer Institute

\section{Source}

National Cancer Institute. Surface Immunoglobulin Positive Cells Present. NCI Thesaurus. Code C150655.

A microscopic finding indicating that immunoglobulins are bound to or expressed on the surface of cells in a sample. 